\title{
A nuclear-directed human pancreatic ribonuclease (PE5) targets the metabolic phenotype of cancer cells
}

\author{
Anna Vert ${ }^{1,2}$, Jessica Castro ${ }^{1,2}$, Marc Ribó ${ }^{1,2}$, Antoni Benito ${ }^{1,2}$, Maria Vilanova ${ }^{1,2}$ \\ ${ }^{1}$ Laboratori d'Enginyeria de Proteïnes, Departament de Biologia, Facultat de Ciències, Universitat de Girona, Girona, \\ Spain \\ ${ }^{2}$ Institut d'Investigació Biomèdica de Girona Josep Trueta, (IdIBGi), Girona, Spain \\ Correspondence to: Maria Vilanova, email: maria.vilanova@udg.edu \\ Antoni Benito, email: antoni.benito@udg.edu
}

Keywords: antitumor drug, human pancreatic ribonuclease, metabolism of cancer cells, microarray profiling, tumor cell death

Received: December 18, 2015

Accepted: February 11, 2016

Published: February 22, 2016

\section{ABSTRACT}

\begin{abstract}
Ribonucleases represent a new class of antitumor RNA-damaging drugs. However, many wild-type members of the vertebrate secreted ribonuclease family are not cytotoxic because they are not able to evade the cytosolic ribonuclease inhibitor. We previously engineered the human pancreatic ribonuclease to direct it to the cell nucleus where the inhibitor is not present. The best characterized variant is PE5 that kills cancer cells through apoptosis mediated by the p21 WAF1/CIP1 induction and the inactivation of JNK. Here, we have used microarray-derived transcriptional profiling to identify PE5 regulated genes on the NCI/ADR-RES ovarian cancer cell line. RT-qPCR analyses have confirmed the expression microarray findings. The results show that PE5 cause pleiotropic effects. Among them, it is remarkable the down-regulation of multiple genes that code for enzymes involved in deregulated metabolic pathways in cancer cells.
\end{abstract}

\section{INTRODUCTION}

Among the special biological actions exhibited by several members of the vertebrate secreted ribonuclease (RNase) family, selective cytotoxicity for cancer cells is one of the most interesting (for reviews see [1-3]). In contrast to many chemotherapeutic drugs currently used in cancer therapy, which target DNA synthesis and transcription, cytotoxic RNases target RNA functions, such as protein synthesis or gene regulation (for a review see [4]) and, therefore, they are non-mutagenic antitumor drugs.

Although the exact mechanism used by RNases to kill cancer cells is not completely understood, from the knowledge gained so far, a multi-step model has been generally accepted. The model postulates that RNases initially interact with the cell membrane and then internalization proceeds via endocytosis. At some point in the endocytic pathway, cytotoxic RNases are translocated to the cytoplasm where they cleave cellular RNA(s), inhibiting protein synthesis and inducing apoptosis. The cytotoxic action of some RNases may be hampered by the action of a potent inhibitor, the ribonuclease inhibitor
(RI) that is found in the cytoplasm of mammalian cells. $\mathrm{RI}$ is a $50 \mathrm{kDa}$ protein that tightly binds to some RNases inhibiting their activity [5]. Thus, the cytotoxic potential of a particular RNase also depends on its ability to by-pass the RI action [6].

The members of the vertebrate secreted RNase family that naturally present cytotoxic activity selective for tumor cells evade the RI. Among them, Onconase ${ }^{\circledR}$ (ONC), an amphibian RNase isolated from oocytes of Rana pipiens, is the paradigm [3]. However, its clinical use has been limited because it induces renal toxicity at high concentrations [7]. In contrast, mammalian pancreatic RNases accumulate to a much lesser extent in kidneys [8], are less immunogenic, display a higher ribonucleolytic activity [9] but are very sensitive to the RI. To endow them with cytotoxic properties, they have been engineered to either evade the RI [10-12] or to be more efficiently delivered into the cells to ensure a competent arrival to the cytosol to saturate the RI $[13,14]$.

We developed another strategy consisting in routing the RNase into the nucleus. Nuclear compartment, or at least its nucleolus, has been described to be free of RI $[15,16]$. We designed and produced nuclear-directed 
human pancreatic RNase (ND-RNase) variants that are cytotoxic for cancer cells $[17,18]$. Among them, the best characterized is PE5, endowed with a non-contiguous extended bipartite nuclear localization signal (NLS) [19]. This NLS binds specifically to $\alpha$-importin [20], which drives the RNase into the nucleolus in a GTP- and Ran-dependent manner [17]. Once there, the ND-RNase cleaves nuclear RNA leaving cytoplasmic RNA unaffected [20]. It has been shown that the introduction of this NLS is necessary for the nuclear transport of PE5 and crucial for its cytotoxicity $[17,19,20]$. In vitro, PE5 selectively kills tumor cells. Its cytotoxicity is produced through apoptosis activating caspases- 8 and -9 and the executioner caspase-3 [21]. It is noteworthy that PE5 induced apoptosis is associated with the $\mathrm{p} 21^{\mathrm{WAF} 1 / \mathrm{CIP} 1}$ induction and the inactivation of JNK. Cell death induced by PE5 also increases the number of cells in S- and G2/M-phases in the NCI/ADR-RES cell line [21]. The cytotoxic effect of PE5 is not prevented by a mutated p53 or a multidrug resistance (MDR) phenotype [21]. Finally, PE5 is synergic with doxorubicin on NCI/ADR-RES cells [22].

To get a deeper insight on the molecular cytotoxic mechanism of PE5, we have used microarray technology to identify significant altered gene expression upon treatment of the NCI/ADR-RES ovarian cancer cell line with PE5. The present work is the first to use microarray-derived transcriptional profiling to identify ND-RNases-regulated genes to understand their cytotoxic effect. It is described that RNases, as RNA-damaging drugs, cause pleiotropic effects [3]. Remarkably, PE5 down-regulates multiple genes that code for enzymes involved in deregulated metabolic pathways in cancer cells. Inhibition of these metabolic processes in cancer cells leads to a significant inhibition of cell growth and induction of cell death. This approach represents a key anticancer strategy that can be used in combination with other antitumor therapies [23-25].

\section{RESULTS}

Since the initial characterization of the cytotoxic mechanism of PE5 was performed in the ovarian cancer cell line, NCI/ADR-RES, we decided to extend the study using microarray technology on the same cell line.

\section{Cell proliferation and RNase sensitivity}

PE5 has ribonucleolytic activity and to get an unbiased approach to examine gene expression by microarray technology, it is very important to search for optimal cell treatment conditions. The RNA population has to be representative of the actual drug effect and not the result of an extensive RNA degradation that would preclude the chance of microarray analysis. In addition, because the induction of apoptosis increases the RNA turnover [26], an extensive cytotoxic effect would generate changes in the RNA levels as a consequence of cellular apoptosis rather than the direct action of the RNase. Therefore, we investigated the cytotoxic effect of PE5 on $\mathrm{NCI} / \mathrm{ADR}-\mathrm{RES}$ cell line at different RNase concentrations and incubation times (Figure S1, Supplementary Data). A dose-dependent cell growth inhibition was apparent after 36 h of incubation with PE5 that increased with time.

Then we analyzed the RNA degradation caused by the different treatments. We incubated NCI/ADR-RES cells with PE5 concentrations that induced a decrease of cell proliferation of $5 \%, 10 \%$, and $15 \%\left(\mathrm{IC}_{5}, \mathrm{IC}_{10}\right.$, and $\mathrm{IC}_{15}$ ) after $36 \mathrm{~h}$ of incubation. We did not analyze higher RNase concentrations because we had previously observed an extensive cleavage of nuclear RNA in HeLa cells incubated with PE5 at a concentration equivalent to $\mathrm{IC}_{20}$ [20]. The RNA degradation of treated and untreated cells was quantified using a bioanalyzer. The RNA integrity obtained after PE5 treatment at the three concentrations, $\mathrm{IC}_{5}, \mathrm{IC}_{10}$, and $\mathrm{IC}_{15}$ gave RIN values of 8.8, 7.9 and 6.60, respectively. Accordingly, we carried out the microarray experiments at a PE5 concentration of $12 \mu \mathrm{M}$ that triggered a decrease of $10 \%$ of cell viability, after $36 \mathrm{~h}$ of treatment, without an extensive RNA degradation.

\section{Gene expression changes in PE5-treated cells}

PE5-treated and untreated NCI/ADR-RES cells revealed 647 differentially expressed genes out of 35,377 present in the microarray (1.83\%). Among them, 47\% were down-regulated (decrease from untreated cells ranged from 2- to 4 -fold) while 53\% were up-regulated in PE5-treated cells (increase from untreated cells ranged from 2- to 106-fold). This suggests that the primary effect of PE5 is both to increase and to decrease gene expression. Among the PE5 down-regulated genes many are known to be involved in cell adhesion and migration (e.g. GPC6, and EFEMP1), amino acid metabolism (e.g. PYCR1, BCAT1, PHGDH and ASNS), lipid metabolism (e.g. HADHA, DHCR24, ACACA and SPTLC3), and glucose metabolism (e.g. PGM1, PGAM1, LDHA and ENO1). In particular, some of them are known to be upregulated in tumor cells enhancing the aggressive nature of tumors (e.g. EFEMP1), promoting migration and invasion of cancer cells (e.g. GPC6) or acting as proto-oncogenes (e.g. MET). Among the PE5 up-regulated genes many are known to be involved in transcription regulation (e.g. HMBOX1, SPEN, RPA4 and MXD1), apoptosis (e.g. BCL2L11, WWOX and BNIP3L), and signaling pathways or transduction (e.g. LRRC2, PPP6R1, RAP1GAP and $\mathrm{CISH})$. Interestingly, some of them function as tumor suppressors (e.g. BCL2L11, MXD1, WWOX, BNIP3L, and DMTF1) or are candidate tumor suppressors having anti-proliferative properties and DNA repair abilities (e.g. LRRC2, RPA4, PPP6R1, SPEN, RAP1GAP and CISH) (see discussion section). Some of the above genes are among the top 20 PE5 up- and down-regulated genes in NCI/ADR-RES cell line (Table S1, Supplementary Data). 


\section{RT-qPCR analysis of gene expression}

mRNA expression of six PE5 down-regulated genes (G6PD, ACACA, PHGDH, IDH2, AKR1A1, and MET) and one up-regulated gene (BCL2L11), representatives of the processes affected by this RNase, were examined by RT-qPCR. The results are presented in Figure S2 of Supplementary Data. Fold changes obtained with RT-qPCR, calculated as the ratio between relative transcript abundance (RTA) values obtained for PE5 treated cells and RTA values obtained for untreated cells, were similar to those found in the microarray analysis (Table 1) confirming that the microarray experiments are fully valid.

\section{Gene ontology analysis and KEGG pathway annotation}

Although the information obtained from individual gene expression changes as a response to PE5 treatment gives clues to the action of this RNase, to better understand the functional relevance of its regulated genes in NCI/ADR-RES cells, we performed a gene ontology analysis. PE5 differentially expressed genes were used to find over-represented gene ontology terms in the three broad ontology categories: "molecular function", that captures the knowledge about the functional activity of gene products, the larger "biological process" as part of which these specific functions collectively act, and "cellular component" where all this occurs. To the same end, PE5 differentially expressed genes were mapped to KEGG database to find overrepresented known metabolic and regulatory pathways. In all cases, a p-value $\leq 0.05$ was considered statistically significant.

Gene ontology analyses showed that PE5 differentially expressed genes are related to different cellular events (Table 2). Among them, we can highlight the biological process ontologies related to lipid and carbohydrate metabolism, response to stress, cell adhesion, proliferation and migration. Interestingly, response to stress term includes genes involved in reactive oxygen species (ROS) quenching and antitumor therapy resistance. Likewise, cell proliferation contains genes that act as tumor suppressors or oncogenes. The individual function of PE5 differentially expressed genes favored nucleotide binding, peptidase activity, and pyrophosphatase activity and they were mainly associated with lysosomes, plasma membrane and anchoring junction.

Analysis of the over-represented pathways collected in the KEGG database showed that 19 pathways were affected by PE5 treatment (Table 3). Most of them were involved in cell metabolism and, of particular interest, are those of pyruvate and glucose metabolism for their relevance in cancer cells [27].

\section{DISCUSSION}

Gene ontology analysis clustered the 647 PE5 affected genes to different terms (Table 2). Among them, we have considered that lipid and carbohydrate metabolism, response to stress and cell adhesion and proliferation are the most relevant to understand how PE5 arrests NC/ADR-RES cell proliferation and induces apoptosis. Moreover, KEGG analysis shows that 11 out of 19 terms are related to metabolic processes (Table 3). Most of the genes involved in these terms are down-regulated. Although they constitute a $47 \%$ of the total affected genes, this percentage significantly increases when considering the genes belonging to the above mentioned terms (Tables 2 and 3). It is tempting to speculate that the expression of up-regulated genes could be due to the cleavage of different microRNAs, as it has been demonstrated for ONC [28]. Further, whereas PE5 down-regulated genes can be clustered in gene ontology and KEGG terms to explain PE5 cytotoxic action, the PE5 up-regulated genes, with the exception of tumor suppressors, cannot. Interestingly, among the 20 more up-regulated genes (Table S1 Supplementary Data), six are candidate tumor suppressors (see below). Thus, although we cannot rule out a role of PE5 up-regulated genes in the cytotoxic mechanism of this drug most of the genes discussed below are down-regulated.

\section{PE5 down-regulates genes coding for enzymes involved in deregulated metabolic pathways in cancer cells}

PE5 down-regulates genes related to glucose metabolism such as phosphoglycerate mutase 1 (PGAM1), enolase 1, (alpha) (ENO1), glucose-6-phosphate dehydrogenase (G6PD), phosphoglycerate dehydrogenase (PHGDH), phosphoserine aminotransferase (PSAT1) and phosphoglucomutase 1 (PGM1). PGAM1 and ENO1 repression produce a decrease in the glycolytic flux associated with a reduction of tumor growth [29-32]. Both genes are over-expressed in different types of cancer [31-34]. G6PD derives the G6P from glycolysis to the pentose phosphate pathway (PPP) (Figure 1), a critical way to obtain both ribose-5-phosphate for biosynthesis and reducing equivalents in form of NADPH, which are used not only for biosynthesis but for scavenging cellular ROS [35]. PHGDH and PSAT1 are critical to derive a significant portion of glycolytic carbon to the biosynthesis of serine and glycine amino acids (Figure 1). PHGDH has been identified as a gene frequently amplified in different cancers [36,37]. PGM1 is an enzyme that can increase the levels of G6P through glycogenolysis. It has been described that glycogen-derived glucose contributes to ATP generation without oxygen requirement, ROS scavenging, and biosynthesis of macromolecules [38]. 
Table 1: Comparison of fold change values obtained by RT-qPCR and gene expression microarray experiments from PE5-treated cells respective to untreated cells

\begin{tabular}{|c|c|c|c|}
\hline Gene Symbol & Gene Name & Fold Change RT-qPCR ${ }^{\text {a }}$ & Fold Change microarrays \\
\hline G6PD & Glucose-6-phosphate dehydrogenase & $-2.18 \pm 0.41$ & -2.20 \\
\hline ACACA & Acetyl-CoA carboxylase alpha & $-2.69 \pm 0.59$ & -2.27 \\
\hline PHGDH & Phosphoglycerate dehydrogenase & $-3.53 \pm 0.74$ & -2.71 \\
\hline IDH2 & $\begin{array}{l}\text { Isocitrate dehydrogenase } 2\left(\mathrm{NADP}^{+}\right) \text {, } \\
\text { mitochondrial }\end{array}$ & $-2.21 \pm 0.34$ & -2.33 \\
\hline AKR1A1 & $\begin{array}{l}\text { Aldo-keto reductase family } 1, \text { member A1 } \\
\text { (aldehyde reductase) }\end{array}$ & $-2.00 \pm 0.24$ & -2.28 \\
\hline MET & $\begin{array}{l}\text { Met proto-oncogene (hepatocyte growth } \\
\text { factor receptor) }\end{array}$ & $-3.00 \pm 0.65$ & -2.60 \\
\hline BCL2L11 & BCL2-like 11 (apoptosis facilitator) & $2.13 \pm 0.25$ & 3.19 \\
\hline
\end{tabular}

PE5 down-regulates the gene coding for lactate dehydrogenase A (LDHA). The acidification of tumor surroundings produced by excreted lactate helps tumor invasion and inhibits the immune system. Moreover, lactate is a gluconeogenic precursor and although the role of gluconeogenesis in cancer is still not well known, the key mitochondrial gluconeogenic enzyme, phophoenolpyruvate carboxykinase 2 mitochondrial (PCK2), also down-regulated by PE5, is expressed in different non-gluconeogenic tissues including tumors [39-41]. Recently [42] it has been demonstrated that in lung cancer cell lines incubated with ${ }^{13} \mathrm{C}$-lactate, the three lactate carbon atoms appear in the phosphoenolpyruvate (PEP) pool, supporting a conversion of lactate to PEP via gluconeogenesis (Figure 1). This suggests that some steps of gluconeogenesis are used to overcome the detrimental metabolic situation generated by aglycemia periods generated by the sustained high rate of cell proliferation [43].

PE5 down-regulates some enzymes involved in the oxidation of fatty acids, a key pathway for energy generation in cancer cells [44]. We can mention propionyl CoA carboxylase beta polypeptide (PCCB), as well as hydroxyacyl-CoA dehydrogenase/3-ketoacyl-CoA thiolase/enoyl-CoA hydratase (trifunctional protein), alpha subunit (HADHA) (Figure 1).

On the other hand, cancer cells are highly dependent on de novo lipid biosynthesis [44]. PE5 down-regulates acetyl-CoA carboxylase, alpha (ACACA) (Figure 1). Citrate is a critical metabolite required to support cytosolic lipid biosynthesis. In cancer cells, TCA cycle anaplerosis is maintained mainly by glutamine $[45,46]$. Glutaminederived $\alpha$-ketoglutarate is reductively carboxylated by isocitrate dehydrogenase 1 or 2 (IDH1, IDH2) to isocitrate/ citrate (Figure 1) [47,48]. NADPH-linked mitochondrial isocitrate dehydrogenase 2 (IDH2) is a PE5-downregulated enzyme. Interestingly, it has recently described that IDH2 is involved in the generation of oncometabolite 2-hydroxiglutarate (2-HG) [49]. Cells have other ways to refurbish TCA cycle [45]. Mitochondrial extruded citrate converted to OAA and acetil-CoA by ATP citrate lyase (ACL) can re-enter the OAA moiety through several steps (Figure 1) that include the PE5 down-regulated NADP ${ }^{+}$dependentmitochondrial malic enzyme 3 (ME3).

The increased fatty acid synthesis leads to the upregulation of the phospholipids [50], sphingolipids [51] and cholesterol biosynthesis [44]. Some genes involved in sphingolipid synthesis have a decreased expression upon PE5 cell treatment: serine palmitoyltransferase long chain base subunit 3 (SPTLC3) and $\mathrm{N}$-acylsphingosine amidohydrolase (acid ceramidase) 1 (ASAH1). PE5 also down-regulates some key enzymes involved in cholesterol synthesis such as 24-dehydrocholesterol reductase (DHCR24), transmembrane 7 superfamily member 2 (TM7SF2), monooxygenase 1 (MSMO1) (Figure 1). It is worth mentioning that deregulation of the mevalonate pathway has been associated with transformation [52-54].

Although we have not found a term in gene ontology and KEGG analysis related to amino acid metabolism it is worth mentioning that PE5 treatment reduces the expression level of genes involved in amino acid biosynthesis other than PHGDH and G6PD described above. These genes are pyrroline-5-carboxylate reductase 1 (PYCR1), asparagine synthetase (ASNS), and the catabolizing amino acid enzyme, branched-chain amino acid transaminase 1 (BCAT1). All three enzymes are found over-expressed in different cancers and ASNS is associated with resistance to L-asparaginase cancer therapy [55-57]. Interestingly, PHGDH, PYCR1 and BCAT1 are among the 20 most PE5 down-regulated genes (Table S1 Supplementary Data).

KEGG analysis shows that PE5 may also inhibit the protein synthesis since it down-regulates many genes coding for aminoacyl tRNA synthetases. These genes 
Table 2: Gene ontology analysis of PE5 differentially expressed genes in NCI/ADR-RES cell line

\begin{tabular}{|c|c|c|c|c|}
\hline Gene Ontology & Gene ontology term & Gene count ${ }^{a}$ & \% Down-regulated genes & P-value \\
\hline \multirow[t]{8}{*}{ Biological Process } & Lipid metabolic process & 64 & 73.44 & $8.11 \mathrm{E}-05$ \\
\hline & Response to stress & 131 & 63.36 & 4.70E-04 \\
\hline & Angiogenesis & 25 & 64.00 & $6.83 \mathrm{E}-04$ \\
\hline & Developmental process & 181 & 61.88 & 4.07E-03 \\
\hline & Cell adhesion & 47 & 65.96 & $8.26 \mathrm{E}-03$ \\
\hline & Cell proliferation & 69 & 49.28 & $1.33 \mathrm{E}-02$ \\
\hline & Cell migration & 41 & 78.05 & $1.61 \mathrm{E}-02$ \\
\hline & Carbohydrate metabolic process & 36 & 69.44 & 4.34E-02 \\
\hline \multirow[t]{8}{*}{ Molecular Function } & Nucleotide binding & 115 & 60.00 & $3.52 \mathrm{E}-05$ \\
\hline & Peptidase activity & 34 & 79.41 & $1.34 \mathrm{E}-03$ \\
\hline & Pyrophosphatase activity & 42 & 50.00 & $2.58 \mathrm{E}-03$ \\
\hline & Oxidoreductase activity & 38 & 68.42 & $3.30 \mathrm{E}-03$ \\
\hline & Monosaccharide binding & 7 & 100.00 & $4.58 \mathrm{E}-03$ \\
\hline & Cytoskeletal protein binding & 34 & 64.71 & $4.95 \mathrm{E}-03$ \\
\hline & Glycoprotein binding & 6 & 66.67 & $1.28 \mathrm{E}-02$ \\
\hline & Coenzyme binding & 12 & 75.00 & $1.77 \mathrm{E}-02$ \\
\hline \multirow[t]{9}{*}{ Cellular Component } & Lysosome & 31 & 90.32 & $2.31 \mathrm{E}-07$ \\
\hline & Plasma membrane & 177 & 64.97 & $1.27 \mathrm{E}-04$ \\
\hline & Anchoring junction & 16 & 81.25 & $1.67 \mathrm{E}-03$ \\
\hline & Endoplasmic reticulum & 61 & 73.77 & $2.25 \mathrm{E}-03$ \\
\hline & Cell surface & 28 & 78.57 & $2.41 \mathrm{E}-03$ \\
\hline & Extracellular region & 92 & 73.91 & $3.05 \mathrm{E}-03$ \\
\hline & Endosome & 29 & 58.62 & $7.86 \mathrm{E}-03$ \\
\hline & Golgi apparatus & 53 & 73.58 & $8.01 \mathrm{E}-03$ \\
\hline & Actin cytoskeleton & 19 & 68.42 & $2.87 \mathrm{E}-02$ \\
\hline
\end{tabular}

${ }^{a}$ Number of differentially expressed genes that belong to these terms.

are cysteinyl-tRNA synthetase (CARS), alanyl-tRNA synthetase (AARS), glycyl-tRNA synthetase (GARS), isoleucyl-tRNA synthetase (IARS), tyrosyl-tRNA synthetase (YARS), and glutamyl-prolyl-tRNA synthetase (EPRS). This is in agreement with our previous results that showed that treatment of different cancer cell lines with PE5 reduces cell protein synthesis compared to untreated cells [17].

\section{PE5 down or up-regulates some oncogenes and tumor suppressor genes, respectively}

Among the genes with oncogenic functions downregulated by PE5, we can mention glypican 6 (GPC6), EGF containing fibulin-like extracellular matrix protein 1
(EFEMP1), met proto-oncogene (hepatocyte growth factor receptor) (MET), transglutaminase 2 (C polypeptide, protein-glutamine-gamma-glutamyltransferase) (TGM2), platelet-derived growth factor receptor, beta polypeptide (PDGFRB), and clusterin (CLU). All of them have been found overexpressed in different tumors where they play different roles ranging from cell proliferation and angiogenic stimulation to invasiveness and metastasis [58-67].

Interestingly, MET, TGM2 and CLU are linked to some deregulated metabolic pathways, inhibited by PE5, through the activation of signaling pathways (Figure 2). The binding of MET with its ligand (hepatocyte growth factor) activates downstream signaling pathways, including phosphoinositide 3-kinase (PI3K)/Akt, Ras- 
Table 3: KEGG pathway annotation of PE5 differentially expressed genes in NCI/ADR-RES cell line

\begin{tabular}{lccc}
\hline KEGG term & Gene count $^{\text {a }}$ & \% Down-regulated genes & P-value \\
\hline Lysosome & 14 & 92.86 & $8.84 \mathrm{E}-05$ \\
Metabolic pathways & 59 & 88.14 & $8.73 \mathrm{E}-04$ \\
Pyruvate metabolism & 6 & 66.67 & $2.64 \mathrm{E}-03$ \\
Steroid biosynthesis & 4 & 100.00 & $3.97 \mathrm{E}-03$ \\
Propanoate metabolism & 5 & 80.00 & $5.01 \mathrm{E}-03$ \\
Glycolysis / Gluconeogenesis & 7 & 85.71 & $7.91 \mathrm{E}-03$ \\
Nicotinate and nicotinamide & 4 & 100.00 & $9.47 \mathrm{E}-03$ \\
metabolism & 7 & 71.43 & $1.56 \mathrm{E}-02$ \\
Gastric acid secretion & 4 & 25.00 & $1.63 \mathrm{E}-02$ \\
Homologous recombination & 2 & 100.00 & $1.72 \mathrm{E}-02$ \\
Vitamin B6 metabolism & 3 & 66.67 & $2.09 \mathrm{E}-02$ \\
Selenocompound metabolism & 3 & 100.00 & $2.09 \mathrm{E}-02$ \\
Other glycan degradation & 6 & 100.00 & $2.38 \mathrm{E}-02$ \\
Aminoacyl-tRNA & 13 & 92.31 & $2.55 \mathrm{E}-02$ \\
biosynthesis & 3 & 66.67 & $2.83 \mathrm{E}-02$ \\
Focal adhesion & 7 & 100.00 & $3.10 \mathrm{E}-02$ \\
Glycosaminoglycan & 6 & 66.67 & $3.75 \mathrm{E}-02$ \\
degradation & 7 & 85.71 & $3.85 \mathrm{E}-02$ \\
ECM-receptor interaction & 50.00 & $3.98 \mathrm{E}-02$ \\
Viral myocarditis & & & \\
Salivary secretion & & & \\
Bile secretion & & &
\end{tabular}

${ }^{a}$ Number of differentially expressed genes that belong to these terms.

Rac/Rho, MAPK, and phospholipase C- $\gamma$ [64], frequently activated in human cancers [68]. TGM2 activates the pro-survival NF-kB [69] and focal adhesion kinase/Akt, whereas it negatively regulates the tumor suppressor phosphatase and tensin homologue (PTEN) [70]. PTEN suppression in malignant cells increases the PI3K system activity [27]. CLU activates the pro-survival Akt [71] while inhibiting the pro-apoptotic Bax [72]. Akt can activate ACL by phosphorylation [73] and activate the expression of several genes involved in fatty acid and cholesterol biosynthesis, such as FASN, ACC, ACL, ACAT, HMGCS and HMGCR, through their effects on the transcription factor family of sterol regulatory element-binding proteins (SREBPs) [74]. One important downstream effector of Akt is the mammalian target of rapamycin complex I (mTORC1), involved in the regulation of several metabolic processes, including protein synthesis [75], whose activity is required for the nuclear accumulation of mature SREBPs. Activation of $\mathrm{PI} 3 \mathrm{~K} / \mathrm{Akt} / \mathrm{mTOR}$ pathway also increases glycolysis and lactate production and is sufficient to induce the Warburg effect [27]. It is also worth mentioning that GPC6, the most PE5 down-regulated gene, belongs to the glypican family of cell surface heparan sulfate proteoglycans [76]. Expression of GPC6 promotes invasive migration through up-regulation of Wnt5A signaling. More interesting, GPC6 induction of Wnt5A stimulates the activation of JNK and p38 MAPK [77]. We have demonstrated that PE5 kills cancer cells through apoptosis associated with the $\mathrm{p} 21^{\mathrm{WAF} 1 / \mathrm{CIP} 1}$ induction and JNK inactivation [21], thus a PE5 down-regulation of GPC6 might contribute to JNK inactivation.

Tumor suppressor genes up-regulated by PE5 treatment are the apoptosis facilitator BCL2-like 11 (BCL2L11), MAX dimerization protein 1 (MXD1), ras homolog gene family, member B (RHOB), BCL2/ adenovirus E1B 19kDa interacting protein 3-like (BNIP3L), cyclin D binding myb-like transcription factor 1 (DMTF1), WW domain containing oxidoreductase (WWOX), and nuclear factor of kappa light polypeptide gene enhancer in B-cells inhibitor, alpha (NFKBIA). All of them play two main roles, apoptosis activation or facilitation [78-81] and 


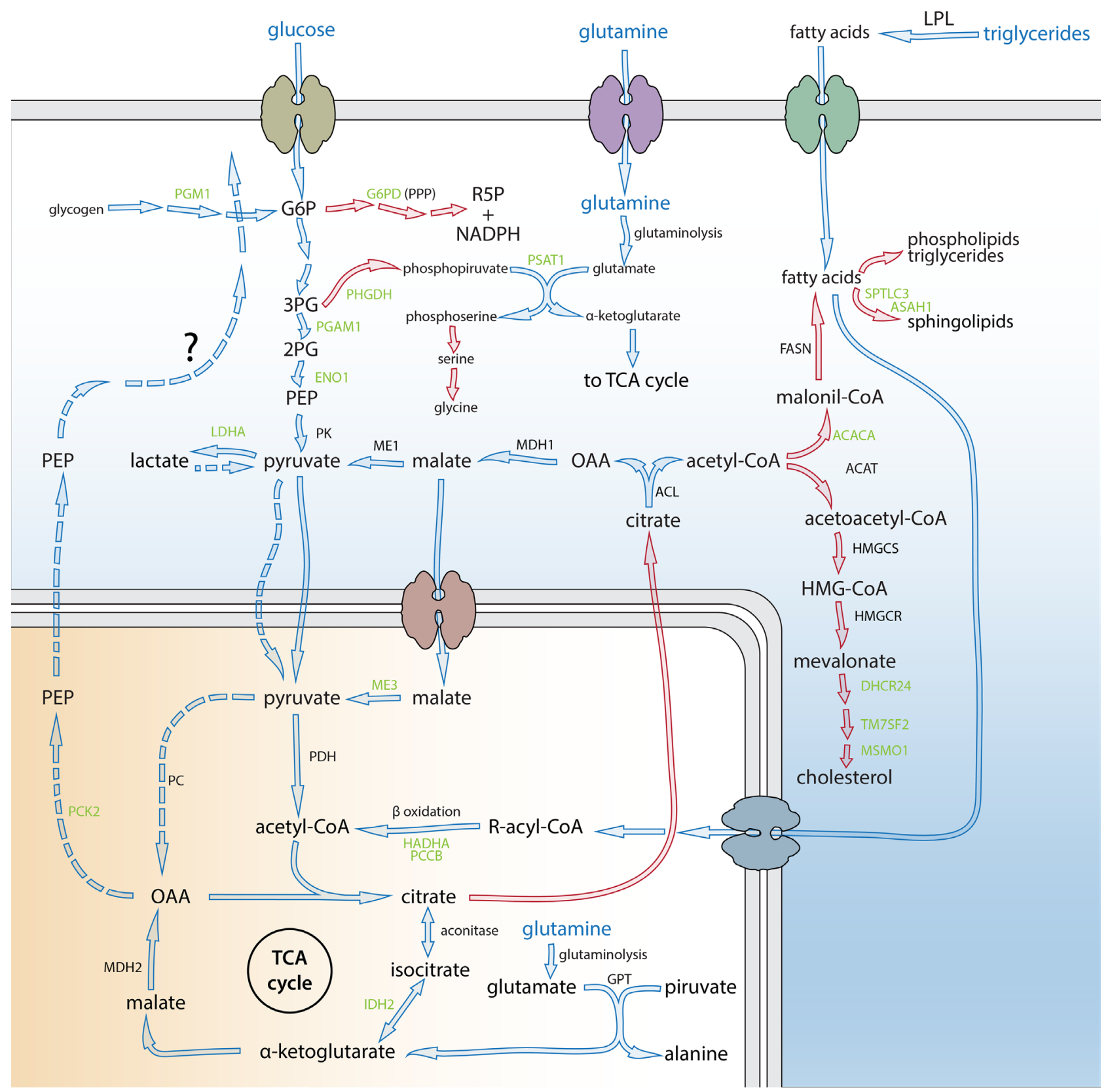

Figure 1: PE5 down-regulated enzymes belonging to deregulated metabolic pathways in cancer. Green, name of the enzymes down-regulated by PE5; blue, metabolites that are the main source of energy for cancer cells depending on their status; blue arrows, catabolic pathways; blue dashed arrows, potential gluconeogenesis not still proved in cancer cells (see text for more details); red arrows, biosynthetic pathways critical for cancer cell grow and division; PPP, pentose phosphate pathway; TCA, tricarboxylic acid; G6P, glucose-6-phosphate; OAA, oxaloacetate; PEP, phosphoenolpyruvate; 2PG, 2-phosphoglycerate; 3PG, 3-phosphoglycerate; HMGCoA, 3-hydroxy-3-methylglutaryl-coenzyme A; R5P, ribose-5-phosphate. Enzymes: ACACA, acetyl-CoA carboxylase alpha; ACAT, acetyl-CoA acetyltransferase; ACL, ATP citrate lyase; ASAH1, N-acylsphingosine amidohydrolase (acid ceramidase) 1; DHCR24, 24-dehydrocholesterol reductase; ENO1, enolase 1, (alpha); FASN, fatty acid synthase; GPT, alanine aminotransferase; G6PD, glucose6-phosphate dehydrogenase; HADHA, hydroxyacyl-CoA dehydrogenase/3-ketoacyl-CoA thiolase/enoyl-CoA hydratase (trifunctional protein), alpha subunit; HMGCR, HMG-CoA reductase; HMGCS, HMG-CoA synthase; IDH2, isocitrate dehydrogenase 2 (NADP ${ }^{+}$), mitochondrial; LDHA, lactate dehydrogenase A; LPL, lipoprotein lipase; MDH1, malate dehydrogenase 1, NAD (soluble); MDH2, malate dehydrogenase 2, NAD (mitochondrial); ME1, malic enzyme 1, NADP ${ }^{+}$-dependent, cytosolic; ME3, malic enzyme 3, NADP ${ }^{+}$-dependent, mitochondrial; MSMO1, methylsterol monooxygenase 1; PC, pyruvate carboxylase; PCCB, propionyl CoA carboxylase, beta polypeptide; PCK2, phophoenolpyruvate carboxykinase 2 (mitochondrial); PDH, pyruvate dehydrogenase complex; PGAM1, phosphoglycerate mutase 1 (brain); PGM1, phosphoglucomutase 1, PHGDH, phosphoglycerate dehydrogenase; PK, pyruvate kinase; PSAT1, phosphoserine aminotransferase 1; SPTLC3, serine palmitoyltransferase, long chain base subunit 3; TM7SF2, transmembrane 7 superfamily member 2. 
oncogene antagonism [82-86]. In addition, among the 20 most PE5 up-regulated genes (Table S1, Supplementary Data) some are candidate tumor suppressors: Leucine rich repeat containing 2 (LRRC2) [87,88], Replication protein A4, 30kDa (RPA4) [89,90], Protein phosphatase 6, regulatory subunit (PPP6R1) [91,92], Spen homolog, transcriptional regulator (Drosophila) (SPEN) [93], RAP1GTPase activating protein (RAP1GAP) [94] and cytokine inducible SH2-containing protein (CISH) [95].

Like oncogenes, some of these tumor suppressor genes are related to metabolic reprogramming of cancer cells (Figure 2). BCL2L11 interacts with all anti-apoptotic members of the Bcl-2 protein family and acts as an apoptotic activator [78]. Loss of even one BCL2L11 allele accelerates Myc-induced development of tumors [96]. MXD1 is considered an antagonist of the oncogene Myc [82]. WWOX interacts with different oncogenic proteins sequestering them in the cytoplasm and thereby inhibiting their oncogenic activity [97-99]. Several oncogenes, like Myc and receptor tyrosine kinases can stimulate the transcription of a number of genes encoding the proteins that mediate glycolysis and glutaminolysis pathways [100]. Moreover, WWOX controls the expression of glycolytic genes through hypoxia-inducible transcription factor- $1 \alpha$ regulation (HIF-1 $\alpha$ ) [101-103]. Therefore, PE5-induced over-expression of BCL2L11, MXD1 and WWOX reinforces the suppression of the metabolic reprograming of cancer cells induced by PE5 downregulated oncogenes described above. NFKBIA inhibits the transcription factor NF-kB [86]. Thus, PE5 can reduce the NF-kB activity both by down-regulating its activator oncogene (TGM2) and by up-regulating its inhibitor (NFKBIA). The NF-kB pathway has been recently described as involved in metabolic reprogramming [104].

\section{PE5 down-regulates genes related to ROS quenching and antitumor therapy resistance}

In addition to the effects mentioned above, PE5 decreases the expression of genes involved in the quenching of ROS. Treatment with PE5 reduces the expression of two genes involved in the detoxification of

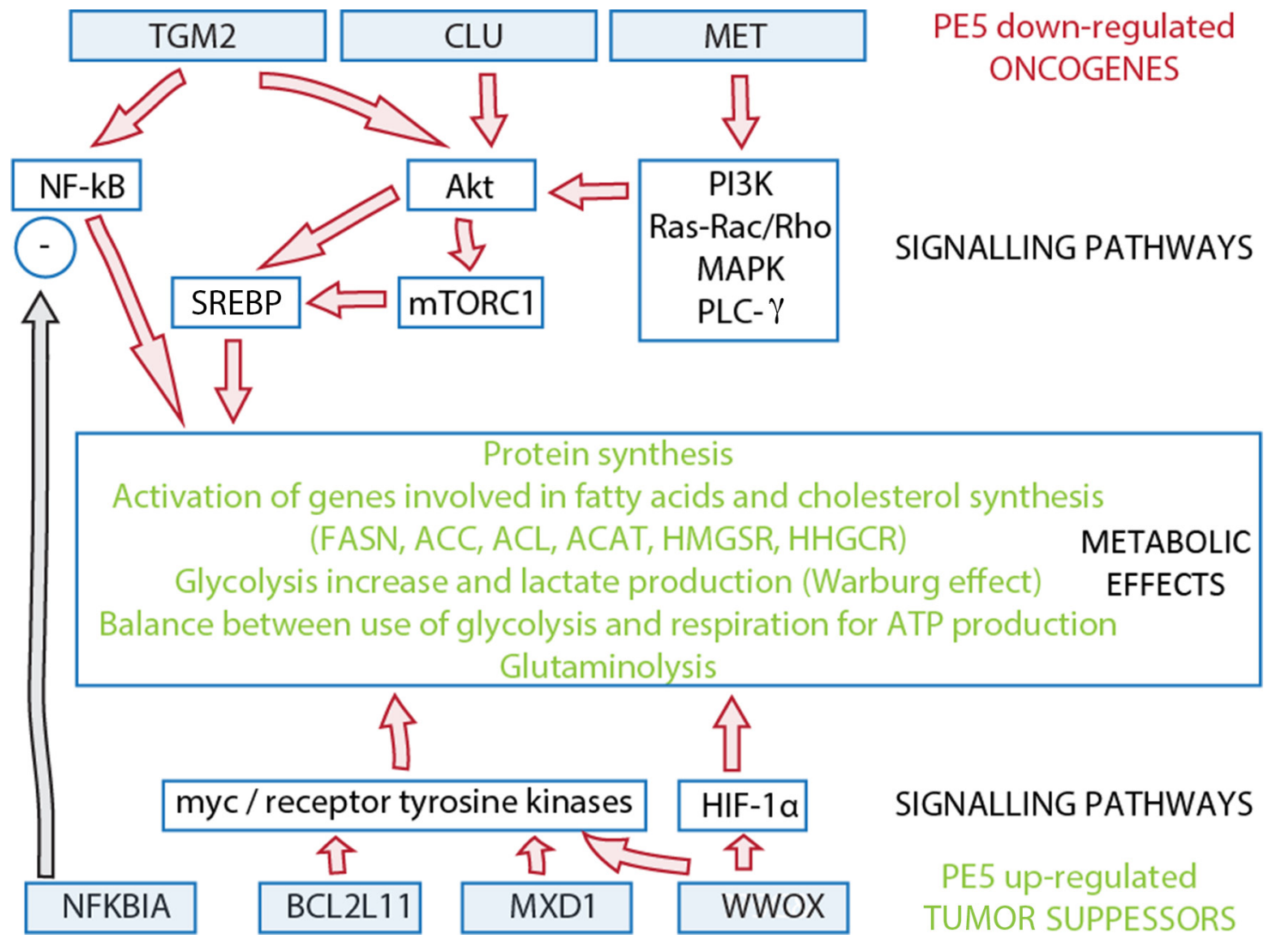

Figure 2: Potential links between PE5 down-regulated oncogenes and up-regulated tumor suppressors and deregulated metabolic pathways through signaling pathways. The PE5 down-regulated oncogenes and the PE5 up-regulated tumor suppressors are shown in the blue boxes while the potential signaling pathways are indicated in the empty boxes. The deregulated metabolic pathways are inhibited by both the down-regulation of the oncogenes and the up-regulation of the tumor suppressor (see text for more details). Genes: BCL2L11, BCL2-like 11 (apoptosis facilitator); CLU, clusterin; MET, met proto-oncogene (hepatocyte growth factor receptor); MXD1, MAX dimerization protein 1; NFKBIA, nuclear factor of kappa light polypeptide gene enhancer in B-cells inhibitor, alpha; TGM2, transglutaminase 2 (C polypeptide, protein-glutamine-gamma-glutamyltransferase); WWOX, WW domain containing oxidoreductase. 
ROS, thioredoxin reductase 2 (TXNRD2) and glutathione peroxidase 3 (GPX3), belonging to thioredoxin [105] and glutathione antioxidant systems [106], respectively. Of note, glutathione and thioredoxin antioxidant systems rely on the reducing power of NADPH to maintain their activities. As stated above, PE5 decreases the expression level of relevant proteins involved in the production of NADPH (G6PD, ME3 and IDH2). Altogether, this reduction can induce apoptosis due to high ROS levels in cancer cells treated with PE5.

On the other hand, reduced glutathione has an important role in a number of drug resistance mechanisms [107]. In addition, some of the above mentioned PE5 down-regulated genes are involved in resistance to antitumor therapy. For instance, MET whose activation is related to resistance to epidermal growth factor receptor inhibitors [108], PDGFRB whose inhibition is associated with an improved tumor drug uptake [109], CLU that interferes with apoptotic signaling and confers resistance to a broad spectrum of anti-cancer treatments [110,111], and ASNS involved in resistance to L-asparaginase [56,112]. Likewise, up-regulation of some of the above stated tumor suppressors such as BCL2L11, RHOB and NFKBIA, contributes to fight against the antitumor drug resistance because they mediate apoptosis induced by several anticancer drugs [113-115]. PE5 also downregulates the expression of two enzymes directly involved in the MDR phenotype: i) aldo-keto reductase family 1 member A1 (AKR1A1) that metabolizes anthracyclines into inactive compounds [116] and has been associated with acquired resistance to irradiation [117]; ii) prosaposin (PSAP), present among the 20 most PE5 downregulated genes (Table S1 Supplementary Data), found overexpressed in ovarian tumors after chemotherapy [118] and involved in estrogen chemotherapy resistance [119].

\section{MATERIALS AND METHODS}

\section{PE5 expression and purification}

Construction of PE5 has been previously described [17]. It was obtained from PM5 (a human pancreatic RNase variant carrying five substitutions at the N-terminus: Arg4Ala, Lys6Ala, Gln9Glu, Asp16Gly, and Ser17Asn [120]) by replacing Gly89 and Ser90 by Arg. PE5 was produced and purified from Escherichia coli BL21(DE3) cells transformed with the corresponding vector essentially as described previously [121]. The molecular mass of PE5 was confirmed by Matrix-assisted laser desorption/ionization time-of-flight (MALDI-TOF) mass spectrometry at Unitat cientificotècnica de suport, Institut de Recerca, Hospital Universitari Vall d'Hebron (Barcelona, Spain). PE5 concentration was determined by ultraviolet spectroscopy using an extinction coefficient at $280 \mathrm{~nm}$ of $7950 \mathrm{M}^{-1} \mathrm{~cm}^{-1}$, calculated as reported previously [122].

\section{Cell line and culture conditions}

NCI/ADR-RES human ovarian cancer MDR cell line (formerly MCF-7/AdrR) [123] was a generous gift of Dr. Ramon Colomer of the Institut Català d'Oncologia de Girona, Hospital Universitari de Girona Dr. Josep Trueta (Girona, Spain). They were initially obtained from American type Culture Collection (ATCC) (Manassas, Virginia) and were used immediately after resuscitation. Cells were routinely grown at $37^{\circ} \mathrm{C}$ in a humidified atmosphere of $5 \% \mathrm{CO}_{2}$ in DMEM (Gibco, Germany) supplemented with $10 \%$ fetal bovine serum (Gibco, Germany), $50 \mathrm{U} / \mathrm{ml}$ penicillin, $50 \mu \mathrm{g} / \mathrm{ml}$ streptomycin (Gibco, Germany), and $1.84 \mu \mathrm{M}$ doxorubicin (TedecMeijic Farma, Spain). Cells remained free of Mycoplasma and were propagated according to established protocols.

\section{Cell proliferation assay}

NCI/ADR-RES cells $\left(10^{4}\right.$ per well $)$ were seeded into 96 -well plates. After $24 \mathrm{~h}$ of incubation, cells were treated for 24,36 , or $48 \mathrm{~h}$ with various concentrations of PE5, ranging from 0.1 to $30 \mu \mathrm{M}$. RNase sensitivity was determined by the MTT method essentially as described by the manufacturer's instructions (Sigma, USA). Data were collected by measuring the absorbance at $570 \mathrm{~nm}$ with a Synergy 4 multi-well plate reader (Biotek Instruments, USA). The $\mathrm{IC}_{5}, \mathrm{IC}_{10}$, and $\mathrm{IC}_{15}$ values represent the concentrations of $\mathrm{PE} 5$ required to inhibit cell proliferation by 5,10 , and $15 \%$, respectively, and were calculated by interpolation from the obtained growth curves. Data are expressed as mean \pm SD of three independent experiments conducted in triplicates.

\section{PE5 treatment and RNA isolation}

NCI/ADR-RES cells $\left(2 \times 10^{5}\right.$ per well) were seeded into 6-well plates. After $24 \mathrm{~h}$ of incubation, cells were treated for $36 \mathrm{~h}$ with a concentration of PE5 that caused a $10 \%$ decrease of cell proliferation $(12 \mu \mathrm{M})$. Cells were then harvested at $400 \mathrm{xg}$ for $5 \mathrm{~min}$ at $4^{\circ} \mathrm{C}$ and washed twice with cold PBS. Total RNA was extracted using the mirVana miRNA isolation kit (Applied Biosystems/ Ambion, USA) according to the manufacturer's instructions and stored at $-80^{\circ} \mathrm{C}$. Four independent preparations were performed. RNA integrity and absorbance $260 / 280 \mathrm{~nm}$ ratio of each sample were checked using an Agilent 2100 Bioanalyzer (Agilent Technologies, USA) and a NanoDrop ND-1000 Spectrophotometer (Thermo Fisher Scientific, USA), respectively.

\section{Gene expression microarray analysis}

Gene expression microarray experiments were performed at Bioarray, S.L. (Alacant, Spain) using the SurePrint G3 Human Gene Expression Microarray (Agilent Technologies, USA), a high-density 
oligonucleotide microarray that contains 60,000 probes that correspond to 27,958 Entrez Gene RNAs and 7,419 lncRNAs. Sample preparation and microarray processing procedures were done according to the TwoColor Microarray-Based Gene Expression Analysis v. 6.5 (Agilent Technologies, USA). Briefly, $200 \mathrm{ng}$ of total RNA were used to synthesize double-stranded cDNA with AffinityScript-Reverse Transcriptase and Oligo dTPromoter Primer. cDNA was simultaneously amplified and transcribed into cyanine 3- or cyanine 5-labeled cRNA employing T7 RNA Polymerase in presence of cyanine 3-CTP or cyanine 5-CTP. The labeled cRNA (antisense) was purified, evaluated using a NanoDrop ND-1000 Spectrophotometer (Thermo Fisher Scientific, USA) and hybridized to the oligonucleotide microarrays at $65^{\circ} \mathrm{C}$ for $17 \mathrm{~h}$. Microarrays were then washed and scanned on a G2565CA Microarray Scanner updated to 2 micron resolution (Agilent Technologies, USA). Data were extracted from the resulting TIFF-images using the Feature Extraction software v. 10.7 (Agilent Technologies, USA). Raw microarray data were statistically analysed using the software packages Marray, pcaMethods, Limma, and RankProd from Bioconductor (www.bioconductor. org), which uses the $\mathrm{R}$ statistical environment and programming language. In particular, the non-specific signal was removed from the total intensity using the Normexp background correction method with an offset of 20 [124]. Then intra-slide normalization was done using the Loess method [125] to make intensities consistent within each array, and inter-slide normalization was performed employing the Aquantiles method [126] to achieve consistency between arrays. After each of these analyses, a quality control analysis of microarray data (RG density plot, MA plot and M boxplot) was performed. Following normalization, the RankProd method [127] was applied to identify differentially expressed genes. Genes were considered differentially expressed when they had a false discovery rate adjusted $\mathrm{p}$-value $\leq 0.05$ and a fold change $\geq 2$ or $\leq-2$.

Data have been deposited in NCBI's Gene Expression Omnibus repository [128] (http://www. ncbi.nih.gov/geo) and are available under the accession number: GSE75494.

\section{Gene ontology analysis and KEGG pathway annotation}

Differentially expressed genes were characterized functionally with an hypergeometric test to find overrepresented gene ontology terms in the three main broad ontologies (biological process, molecular function, and cellular component) (www.geneontology.org), and were also mapped to the Kyoto Encyclopedia of Genes and Genomes (KEGG) (www.kegg.jp), which assigns proteins to pathways, to find over-represented pathways. The analyses were done using the software packages GOstats and RamiGO from Bioconductor (www.bioconductor.org). A p-value cutoff of 0.05 was used.

\section{Quantitative reverse transcription PCR (RT- qPCR)}

mRNA expression of six PE5 down-regulated genes (G6PD, ACACA, PHGDH, IDH2, AKR1A1, and MET) and one up-regulated gene (BCL2L11) were examined by quantitative real-time PCR. The same RNA samples used for microarrays analysis were used for performing this analysis. First, RNA samples were digested with DNase to prevent genomic contamination using the RNase-Free DNase Set (Qiagen, Germany) according to the manufacturer's instructions, and were evaluated using an Agilent 2100 Bioanalyzer (Agilent Technologies, USA) and a NanoDrop ND-1000 Spectrophotometer (Thermo Fisher Scientific, USA). Then, for each sample, $0.5 \mu \mathrm{g}$ of RNA were used to synthetize single-stranded cDNA with the High-Capacity cDNA Reverse Transcription Kit (Applied Biosystems, USA) following the manufacturer's instructions. Gene-specific forward and reverse primers for the selected genes were designed with Primer3 (http:// primer3.ut.ee) and checked with NetPrimer (http://www. premierbiosoft.com/netprimer/). Primer sequences are indicated in Tables S2 and S3 of Supplementary Data for constitutive and target genes, respectively. Realtime PCRs were performed in an optical 96-well plate with an ABI PRISM 7300 Sequence Detector System (Applied Biosystems, USA), using SYBR Green to monitor dscDNA synthesis. Reactions contained 1x Power SYBR Green PCR Master Mix (Applied Biosystems, USA), $300 \mathrm{nM}$ of gene-specific forward primer, 300 $\mathrm{nM}$ of gene-specific reverse primer, and $5 \mu \mathrm{l}$ of a 50 fold dilution of the previously synthesized cDNA in a final volume of $20 \mu \mathrm{l}$. The following standard thermal profile was used for all real-time PCRs: $95^{\circ} \mathrm{C}$ for 10 min, 40 cycles of $95^{\circ} \mathrm{C}$ for $15 \mathrm{~s}$ and $60^{\circ} \mathrm{C}$ for $1 \mathrm{~min}$. A dissociation step was performed after amplification to confirm the presence of a single amplicon. To estimate variation in the technique, three technical replicates were carried out for each cDNA sample. Data were analyzed with the 7300 SDS 1.3.1 software (Applied Biosystems, USA). To generate a baseline-subtracted plot of the logarithmic increase in fluorescence signal $(\Delta R n)$ versus cycle number, baseline data were collected between cycles 3 and 15. All amplification plots were analyzed with an $\mathrm{Rn}$ threshold of 0.2 to obtain threshold cycle $(\mathrm{Ct})$ values. The amplification efficiency for each gene was calculated based on five dilutions of cDNA ranging from 1 to $3,2 \times 10^{-4}$ and the equation $\mathrm{E}=10^{(-1 / \text { slope })}$. All genes had an efficiency value between 1.85 and 2.05. To select a constitutive gene as a reference for normalizing data, the transcription abundances of five genes (ACTB, GUSB, TBP, HPRT1, and ALAS1) were measured for all cDNA samples. Among them, TBP showed the highest 
stability (lower standard deviation of the $\mathrm{Ct}$ ) (Figure S3, Supplementary Data) and therefore was selected as the reference gene for normalizing data. For the target genes (G6PD, ACACA, PHGDH, IDH2, AKR1A1, MET, and BCL2L11), the relative transcription abundances were calculated as RTA $=\mathrm{E}^{\Delta \mathrm{Ct} \text { (control-sample) }}$ (Target) $/ \mathrm{E}^{\Delta \mathrm{Ct} \text { (control- }}$

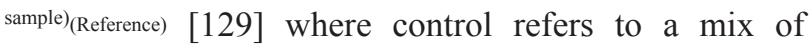
equal amounts of untreated samples. Fold changes were calculated as the ratio between RTA values obtained for PE5 treated cells and those obtained for untreated cells. The absence of genomic DNA contamination was checked using non-retrotranscriptase controls and the absence of environmental contamination using non-template controls.

\section{CONCLUSION}

During the past decade, cancer metabolism has emerged as one of the most exciting and promising fields for the development of selective anticancer therapies. The development of cancer metabolism inhibitors and their synergy with traditional therapeutic approaches may represent a fundamental change and a promising strategy to overcome resistance in cancer therapy, a phenomenon that unfortunately is cause of treatment failure and recidivism in cancer patients. However, new anticancer drugs have to tackle with the multifactorial phenotype of tumor cells. PE5 significantly inhibits genes that belong to metabolic pathways deregulated in cancer cells and it has the plus of presenting pleiotropic effects. Thus, NDRNases are very interesting antitumor agents because they can cope with the complex cancer cell phenotype. In addition, their multiple effects allow anticipating synergism with many at present antitumor drugs used in clinical.

\section{ACKNOLEDGMENTS}

We are very grateful to Dra. M. Figueras, Dra. O. Serra, and P. Boher from the Department of Biology, Universitat de Girona for their help with the RT-qPCR experiments and to Dr. P. Tubert for his invaluable help in the design of figures.

\section{CONFLICTS OF INTEREST}

The authors declare no potential conflicts of interest

\section{GRANT SUPPORT}

This work has been supported by grants BFU200906935 and BIO2013-43517 from MINECO (Spain) and SING12/0 from UdG (Spain). A.V. acknowledges a predoctoral FPU fellowship from Ministerio de Educación y Ciencia (Spain).

\section{REFERENCES}

1. Fang EF, Ng TB. Ribonucleases of different origins with a wide spectrum of medicinal applications. Biochimica et Biophysica Acta - Reviews on Cancer. 2011; 1815:65-74.

2. Ardelt W, Ardelt B, Darzynkiewicz Z. Ribonucleases as potential modalities in anticancer therapy. European Journal of Pharmacology. 2009; 625:181-189.

3. Ribó M, Benito A, Vilanova M. Antitumor ribonucleases in Ribonucleases. Nucleic Acids and Molecular Biology (Nicholson AW, Ed.) Springer Berlin Heidelberg 2011; Vol. 26. pp. 55-88.

4. Tafech A, Bassett T, Sparanese D, Lee CH. Destroying RNA as a therapeutic approach. Current medicinal chemistry. 2006; 13:863-881.

5. Dickson KA, Haigis MC, Raines RT. Ribonuclease Inhibitor: Structure and Function. Progress in Nucleic Acid Research and Molecular Biology. 2005; 80:349-374.

6. Benito A, Vilanova M, Ribó M. Intracellular routing of cytotoxic pancreatic-type ribonucleases. Current pharmaceutical biotechnology. 2008; 9:169-179.

7. Vasandani VM, Burris JA, Sung C. Reversible nephrotoxicity of onconase and effect of lysine $\mathrm{pH}$ on renal onconase uptake. Cancer Chemotherapy and Pharmacology. 1999; 44:164-169.

8. Vasandani VM, Wu YN, Mikulski SM, Youle RJ, Sung C. Molecular determinants in the plasma clearance and tissue distribution of ribonucleases of the ribonuclease A superfamily. Cancer Research. 1996; 56:4180-4186.

9. Matoušek J. Ribonucleases and their antitumor activity. Comparative Biochemistry and Physiology - C Toxicology and Pharmacology. 2001; 129:175-191.

10. Leland PA, Schultz LW, Kim BM, Raines RT. Ribonuclease A variants with potent cytotoxic activity. Proceedings of the National Academy of Sciences of the United States of America. 1998; 95:10407-10412.

11. Leland PA, Staniszewski KE, Kim BM, Raines RT, Endowing Human Pancreatic Ribonuclease with Toxicity for Cancer Cells. The Journal of Biological Chemistry. 2001; 276:43095-43102.

12. Piccoli R, Di Gaetano S, De Lorenzo C, Grauso M, Monaco C, Spalletti-Cernia D, Laccetti P, Cinátl J, Matousek J, D'Alessio G. A dimeric mutant of human pancreatic ribonuclease with selective cytotoxicity toward malignant cells. Proceedings of the National Academy of Sciences of the United States of America. 1999; 96:7768-7773.

13. Ilinskaya ON, Dreyer F, Mitkevich VA, Shaw KL, Pace $\mathrm{CN}$, Makarov AA. Changing the net charge from negative to positive makes ribonuclease Sa cytotoxic. Protein science: a publication of the Protein Society. 2002; 11:2522-2525.

14. Menzel C, Schirrmann T, Konthur Z, Jostock T, Dübel S. Human antibody RNase fusion protein targeting CD30+ lymphomas. Blood. 2008; 111:3830-3837. 
15. Roth JS, Juster H. On the absence of ribonuclease inhibitor in rat liver nuclei. Biochimica et Biophysica Acta (BBA) Nucleic Acids and Protein Synthesis. 1972; 287:474-476.

16. Furia A, Moscato M, Calì G, Pizzo E, Confalone E, Amoroso MR, Esposito F, Nitsch L, D'Alessio G. The ribonuclease/angiogenin inhibitor is also present in mitochondria and nuclei. FEBS letters. 2011; 585:613-617.

17. Bosch M, Benito A, Ribó M, Puig T, Beaumelle B, Vilanova M. A Nuclear Localization Sequence Endows Human Pancreatic Ribonuclease with Cytotoxic Activity. Biochemistry. 2004; 43:2167-2177.

18. Vert A, Castro J, Ruiz-Martínez S, Tubert P, Escribano D, Ribó M, Vilanova M, Benito A. Generation of new cytotoxic human ribonuclease variants directed to the nucleus. Molecular Pharmaceutics. 2012; 9:2894-2902.

19. Rodríguez M, Benito A., Tubert P, Castro J, Ribó M, Beaumelle B, Vilanova M. A Cytotoxic Ribonuclease Variant with a Discontinuous Nuclear Localization Signal Constituted by Basic Residues Scattered Over Three Areas of the Molecule. Journal of Molecular Biology. 2006; 360:548-557.

20. Tubert P, Rodríguez M, Ribó M, Benito A, Vilanova M. The nuclear transport capacity of a human-pancreatic ribonuclease variant is critical for its cytotoxicity. Investigational New Drugs. 2011; 29:811-817.

21. Castro J, Ribó M, Navarro S, Nogués MV, Vilanova $\mathrm{M}$, Benito A. A human ribonuclease induces apoptosis associated with p21WAF1/CIP1 induction and JNK inactivation. BMC cancer. 2011; 11:9.

22. Castro J, Ribó M, Puig T, Colomer R, Vilanova M, Benito A. A cytotoxic ribonuclease reduces the expression level of P-glycoprotein in multidrug-resistant cell lines. Investigational New Drugs. 2012; 30:880-888.

23. Galluzzi L, Kepp O, Vander Heiden MG, Kroemer G. Metabolic targets for cancer therapy. Nature reviews. Drug discovery. 2013; 12:829-846.

24. Zhao Y, Butler EB, Tan M. Targeting cellular metabolism to improve cancer therapeutics. Cell death \& disease. 2013; 4:e532.

25. Sborov DW, Haverkos BM, Harris PJ. Investigational cancer drugs targeting cell metabolism in clinical development. Expert opinion on investigational drugs. 2015; 24:79-94.

26. Mondino A, Jenkins MK. Accumulation of sequencespecific RNA-binding proteins in the cytosol of activated $\mathrm{T}$ cells undergoing RNA degradation and apoptosis. The Journal of biological chemistry. 1995; 270:26593-26601.

27. DeBerardinis RJ, Lum JJ, Hatzivassiliou G, Thompson CB. The biology of cancer: metabolic reprogramming fuels cell growth and proliferation. Cell metabolism. 2008; 7:11-20.

28. Qiao M, Zu L-D, He X-H, Shen R.-L, Wang Q-C, Liu M-F. Onconase downregulates microRNA expression through targeting microRNA precursors. Cell research. 2012; 22:1199-1202.
29. Ren F, Wu H, Lei Y, Zhang H, Liu R, Zhao Y, Chen X, Zeng D, Tong A, Chen L, Wei Y, Huang C. Quantitative proteomics identification of phosphoglycerate mutase 1 as a novel therapeutic target in hepatocellular carcinoma. Molecular cancer. 2010; 9:81.

30. Hitosugi T, Zhou L, Elf S, Fan J, Kang H-B, Seo JH, Shan C, Dai Q, Zhang L, Xie J, Gu T-L, Jin P, Aleckovic M, et al. Phosphoglycerate mutase 1 coordinates glycolysis and biosynthesis to promote tumor growth. Cancer cell. 2012; 22:585-600.

31. Altenberg B, Greulich KO. Genes of glycolysis are ubiquitously overexpressed in 24 cancer classes. Genomics. 2004; 84:1014-1020.

32. Li C, Xiao Z, Chen Z, Zhang X, Li J, Wu X, Li X, Yi H, Li M, Zhu G, Liang S. Proteome analysis of human lung squamous carcinoma. Proteomics. 2006; 6:547-558.

33. Fang MZ, Liu C, Song Y, Yang G-Y, Nie Y, Liao J, Zhao X, Shimada Y, Wang L-D, Yang CS. Over-expression of gastrin-releasing peptide in human esophageal squamous cell carcinomas. Carcinogenesis. 2004; 25:865-871.

34. Turhani D, Krapfenbauer K, Thurnher D, Langen H, Fountoulakis M. Identification of differentially expressed, tumor-associated proteins in oral squamous cell carcinoma by proteomic analysis. Electrophoresis. 2006; 27:1417-1423.

35. Jiang P, Du W, Wu M. Regulation of the pentose phosphate pathway in cancer. Protein \& cell. 2014; 5:592-602.

36. Locasale JW, Grassian AR, Melman T, Lyssiotis CA, Mattaini KR, Bass AJ, Heffron G, Metallo CM, Muranen T, Sharfi H, Sasaki AT, Anastasiou D, Mullarky E, et al. Phosphoglycerate dehydrogenase diverts glycolytic flux and contributes to oncogenesis. Nature genetics. 2011; 43:869-874.

37. Possemato R, Marks KM, Shaul YD, Pacold ME, Kim D, Birsoy K, Sethumadhavan S, Woo H-K, Jang HG, Jha AK, Chen WW, Barrett FG, Stransky N, et al. Functional genomics reveal that the serine synthesis pathway is essential in breast cancer. Nature. 2011; 476:346-350.

38. Zois CE, Favaro E, Harris AL. Glycogen metabolism in cancer. Biochemical pharmacology. 2014; 92:3-11.

39. Méndez-Lucas A, Hyroššová P, Novellasdemunt L, Viñals F, Perales JC. Mitochondrial phosphoenolpyruvate carboxykinase (PEPCK-M) is a pro-survival, endoplasmic reticulum (ER) stress response gene involved in tumor cell adaptation to nutrient availability. The Journal of biological chemistry. 2014; 289:22090-22102.

40. Liu Y-X, Zhang S-F, Ji Y-H, Guo S-J, Wang G-F, Zhang G-W. Whole-exome sequencing identifies mutated PCK2 and HUWE1 associated with carcinoma cell proliferation in a hepatocellular carcinoma patient. Oncology letters. 2012; 4:847-851.

41. Chaika N V, Yu F, Purohit V, Mehla K, Lazenby AJ, DiMaio D, Anderson JM, Yeh JJ, Johnson KR, Hollingsworth MA, Singh PK. Differential expression 
of metabolic genes in tumor and stromal components of primary and metastatic loci in pancreatic adenocarcinoma. PloS one. 2012; 7:e32996.

42. Leithner K, Hrzenjak A, Trötzmüller M, Moustafa T, Köfeler HC, Wohlkoenig C, Stacher E, Lindenmann J, Harris AL, Olschewski A, Olschewski H. PCK2 activation mediates an adaptive response to glucose depletion in lung cancer. Oncogene. 2015; 34:1044-1050.

43. Sonveaux P, Végran F, Schroeder T, Wergin MC, Verrax J, Rabbani ZN, De Saedeleer CJ, Kennedy KM, Diepart C, Jordan BF, Kelley Mj, Gallez B, Wahl ML, et al. Targeting lactate-fueled respiration selectively kills hypoxic tumor cells in mice. The Journal of clinical investigation. 2008; 118:3930-3942.

44. Santos CR, Schulze A. Lipid metabolism in cancer. FEBS Journal. 2012; 279:2610-2623.

45. Moreadith RW, Lehninger AL. The pathways of glutamate and glutamine oxidation by tumor cell mitochondria. Role of mitochondrial NAD $(\mathrm{P})+$-dependent malic enzyme. The Journal of biological chemistry. 1984; 259:6215-6221.

46. DeBerardinis RJ, Mancuso A, Daikhin E, Nissim I, Yudkoff M, Wehrli S, Thompson CB. Beyond aerobic glycolysis: transformed cells can engage in glutamine metabolism that exceeds the requirement for protein and nucleotide synthesis. Proceedings of the National Academy of Sciences of the United States of America. 2007; 104:19345-19350.

47. Metallo CM, Gameiro PA, Bell EL, Mattaini KR, Yang J, Hiller K, Jewell CM, Johnson ZR, Irvine DJ, Guarente L, Kelleher JK, Vander Heiden MG, Iliopouloset O, et al. Reductive glutamine metabolism by IDH1 mediates lipogenesis under hypoxia. Nature. 2012; 481:380-384.

48. Mullen AR, Wheaton WW, Jin ES, Chen P-H, Sullivan LB, Cheng T, Yang Y, Linehan WM, Chandel NS, DeBerardinis RJ. Reductive carboxylation supports growth in tumour cells with defective mitochondria. Nature. 2012; 481:385-388.

49. Wise DR, Ward PS, Shay JES, Cross JR, Gruber JJ, Sachdeva UM, Platt JM, DeMatteo RG, Simon MC, Thompson CB. Hypoxia promotes isocitrate dehydrogenase-dependent carboxylation of $\alpha$-ketoglutarate to citrate to support cell growth and viability. Proceedings of the National Academy of Sciences of the United States of America. 2011; 108:19611-19616.

50. Zhang F, Du G. Dysregulated lipid metabolism in cancer. World journal of biological chemistry. 2012; 3:167-174.

51. Don AS, Lim XY, Couttas TA. Re-configuration of sphingolipid metabolism by oncogenic transformation. Biomolecules. 2014; 4:315-353.

52. Hager MH, Solomon KR, Freeman MR. The role of cholesterol in prostate cancer. Current opinion in clinical nutrition and metabolic care. 2006; 9:379-385.

53. Llaverias G, Danilo C, Mercier I, Daumer K, Capozza F, Williams TM, Sotgia F, Lisanti MP, Frank PG. Role of cholesterol in the development and progression of breast cancer. The American journal of pathology. 2011; 178:402-412.

54. Clendening JW, Pandyra A, Boutros PC, El Ghamrasni S, Khosravi F, Trentin GA, Martirosyan A, Hakem A, Hakem R, Jurisica I, Penn LZ. Dysregulation of the mevalonate pathway promotes transformation. Proceedings of the National Academy of Sciences of the United States of America. 2010; 107:15051-15056.

55. Roth U, Razawi H, Hommer J, Engelmann K, Schwientek T, Müller S, Baldus SE, Patsos G, Corfield AP, Paraskeva C, Hanisch FG. Differential expression proteomics of human colorectal cancer based on a syngeneic cellular model for the progression of adenoma to carcinoma. Proteomics. 2010; 10:194-202.

56. Lorenzi PL, Weinstein JN. Asparagine synthetase: a new potential biomarker in ovarian cancer. Drug news \& perspectives. 2009; 22:61-64.

57. Zhou W, Feng X, Ren C, Jiang X, Liu W, Huang W, Liu Z, Li Z, Zeng L, Wang L, Zhu B, Shi J, Liu J, et al. Overexpression of BCAT1, a c-Myc target gene, induces cell proliferation, migration and invasion in nasopharyngeal carcinoma. Molecular cancer. 2013; 12:53.

58. Gromova P, Ralea S, Lefort A, Libert F, Rubin BP, Erneux C, Vanderwinden J-M. Kit K641E oncogene up-regulates Sprouty homolog 4 and trophoblast glycoprotein in interstitial cells of Cajal in a murine model of gastrointestinal stromal tumours. Journal of cellular and molecular medicine. 2009; 13:1536-1548.

59. Hu B, Thirtamara-Rajamani KK, Sim H, Viapiano MS. Fibulin-3 is uniquely upregulated in malignant gliomas and promotes tumor cell motility and invasion. Molecular cancer research: MCR. 2009; 7:1756-1770.

60. Seeliger H, Camaj P, Ischenko I, Kleespies A, De Toni EN, Thieme SE, Blum H, Assmann G, Jauch K-W, Bruns CJ. EFEMP1 expression promotes in vivo tumor growth in human pancreatic adenocarcinoma. Molecular cancer research: MCR. 2009; 7:189-198.

61. Song E-L, Hou Y-P, Yu S-P, Chen S-G, Huang J-T, Luo T, Kong L-P, Xu J, Wang H-Q. EFEMP1 expression promotes angiogenesis and accelerates the growth of cervical cancer in vivo. Gynecologic oncology. 2011; 121:174-180.

62. Chen Z, Ma T, Huang C, Zhang L, Lv X, Xu T, Hu T, Li J. MiR-27a modulates the MDR1/P-glycoprotein expression by inhibiting FZD7/ $\beta$-catenin pathway in hepatocellular carcinoma cells. Cellular signalling. 2013; 25:2693-2701.

63. En-lin S, Sheng-guo C, Hua-qiao W. The expression of EFEMP1 in cervical carcinoma and its relationship with prognosis. Gynecologic oncology. 2010; 117:417-422.

64. Benvenuti S, Comoglio PM. The MET receptor tyrosine kinase in invasion and metastasis. Journal of cellular physiology. 2007; 213:316-325.

65. Mehta K, Kumar A, Kim HI. Transglutaminase 2: a multitasking protein in the complex circuitry of inflammation and cancer. Biochemical pharmacology. 2010; 80:1921-1929. 
66. Ostman A, Heldin C-H. PDGF receptors as targets in tumor treatment. Advances in cancer research. 2007; 97:247-274.

67. Jones SE, Jomary C. Clusterin. The international journal of biochemistry \& cell biology. 2002; 34:427-431.

68. Cully M, You H, Levine AJ, Mak TW. Beyond PTEN mutations: the PI3K pathway as an integrator of multiple inputs during tumorigenesis. Nature reviews. Cancer. 2006; 6:184-192.

69. Mann AP, Verma A, Sethi G, Manavathi B, Wang H, Fok JY, Kunnumakkara AB, Kumar R, Aggarwal BB, Mehta $\mathrm{K}$. Overexpression of tissue transglutaminase leads to constitutive activation of nuclear factor-kappaB in cancer cells: delineation of a novel pathway. Cancer research. 2006; 66:8788-8795.

70. Verma A, Guha S, Wang H, Fok JY, Koul D, Abbruzzese J, Mehta K. Tissue transglutaminase regulates focal adhesion kinase/AKT activation by modulating PTEN expression in pancreatic cancer cells. Clinical cancer research. 2008; 14:1997-2005.

71. Ammar H, Closset JL. Clusterin activates survival through the phosphatidylinositol 3-kinase/Akt pathway. The Journal of biological chemistry. 2008; 283:12851-12861.

72. Trougakos IP, Lourda M, Antonelou MH, Kletsas D, Gorgoulis VG, Papassideri IS, Zou Y, Margaritis LH, Boothman DA, Gonos ES. Intracellular clusterin inhibits mitochondrial apoptosis by suppressing p53-activating stress signals and stabilizing the cytosolic $\mathrm{Ku} 70$ Bax protein complex. Clinical cancer research. 2009; 15:48-59.

73. Berwick DC, Hers I, Heesom KJ, Moule SK, Tavare JM. The identification of ATP-citrate lyase as a protein kinase $\mathrm{B}$ (Akt) substrate in primary adipocytes. The Journal of biological chemistry. 2002; 277:33895-33900.

74. Porstmann T, Griffiths B, Chung Y-L, Delpuech O, Griffiths JR, Downward J, Schulze A. PKB/Akt induces transcription of enzymes involved in cholesterol and fatty acid biosynthesis via activation of SREBP. Oncogene. 2005; 24:6465-6481.

75. Zoncu R, Efeyan A, Sabatini DM. mTOR: from growth signal integration to cancer, diabetes and ageing. Nature reviews. Molecular cell biology. 2011; 12:21-35.

76. Filmus J, Capurro M, Rast J. Glypicans. Genome biology. 2008; 9:224.

77. Yiu GK, Kaunisto A, Chin YR, Toker A. NFAT promotes carcinoma invasive migration through glypican-6. The Biochemical journal. 2011; 440:157-166.

78. Chen L, Willis SN, Wei A, Smith BJ, Fletcher JI, Hinds MG, Colman PM, Day CL, Adams JM, Huang DCS. Differential targeting of prosurvival Bcl-2 proteins by their BH3-only ligands allows complementary apoptotic function. Molecular cell. 2005; 17:393-403.
79. Couderc B, Pradines A, Rafii A, Golzio M, Deviers A, Allal C, Berg D, Penary M, Teissie J, Favre G. In vivo restoration of RhoB expression leads to ovarian tumor regression. Cancer gene therapy. 2008; 15:456-464.

80. Matsushima M, Fujiwara T, Takahashi E, Minaguchi T, Eguchi Y, Tsujimoto Y, Suzumori K, Nakamura Y. Isolation, mapping, and functional analysis of a novel human cDNA (BNIP3L) encoding a protein homologous to human NIP3. Genes, chromosomes \& cancer. 1998; 21:230-235.

81. Imazu T, Shimizu S, Tagami S, Matsushima M, Nakamura Y, Miki T, Okuyama A, Tsujimoto Y. Bcl-2/E1B 19 kDainteracting protein 3-like protein (Bnip3L) interacts with bcl-2/Bcl-xL and induces apoptosis by altering mitochondrial membrane permeability. Oncogene. 1999; 18:4523-4529.

82. Grandori C, Cowley SM, James LP, Eisenman RN. The $\mathrm{Myc} / \mathrm{Max} / \mathrm{Mad}$ network and the transcriptional control of cell behavior. Annual review of cell and developmental biology. 2000; 16:653-699.

83. Inoue $\mathrm{K}$, Roussel MF, Sherr CJ. Induction of ARF tumor suppressor gene expression and cell cycle arrest by transcription factor DMP1. Proceedings of the National Academy of Sciences of the United States of America. 1999; 96:3993-3998.

84. Zhu S, Mott RT, Fry EA, Taneja P, Kulik G, Sui G, Inoue K. Cooperation between Dmp1 loss and cyclin D1 overexpression in breast cancer. The American journal of pathology. 2013; 183:1339-1350.

85. Salah Z, Aqeilan R, Huebner K. WWOX gene and gene product: tumor suppression through specific protein interactions. Future oncology (London, England). 2010; 6:249-259.

86. Jacobs MD, Harrison SC. Structure of an IkappaBalpha/ NF-kappaB complex. Cell. 1998; 95:749-758.

87. Kiss H, Yang Y, Kiss C, Andersson K, Klein G, Imreh $\mathrm{S}$, Dumanski JP. The transcriptional map of the common eliminated region 1 (C3CER1) in 3p21.3. European journal of human genetics: EJHG. 2002; 10:52-61.

88. Kholodnyuk ID, Kozireva S, Kost-Alimova M, Kashuba $\mathrm{V}$, Klein G, Imreh S. Down regulation of $3 p$ genes, LTF, SLC38A3 and DRR1, upon growth of human chromosome 3-mouse fibrosarcoma hybrids in severe combined immunodeficiency mice. International journal of cancer. 2006; 119:99-107.

89. Kemp MG, Mason AC, Carreira A, Reardon JT, Haring SJ, Borgstahl GEO, Kowalczykowski SC, Sancar A, Wold MS. An alternative form of replication protein a expressed in normal human tissues supports DNA repair. The Journal of Biological Chemistry. 2010; 285:4788-4797.

90. Haring SJ, Humphreys TD, Wold MS. A naturally occurring human RPA subunit homolog does not support DNA replication or cell-cycle progression. Nucleic acids research. 2010; 38:846-858. 
91. Zeng K, Bastos RN, Barr F a., Gruneberg U. Protein phosphatase 6 regulates mitotic spindle formation by controlling the T-loop phosphorylation state of Aurora A bound to its activator TPX2. Journal of Cell Biology. 2010; 191:1315-1332.

92. Douglas P, Zhong J, Ye R, Moorhead GBG, Xu X, Lees-Miller SP. Protein Phosphatase 6 Interacts with the DNA-Dependent Protein Kinase Catalytic Subunit and Dephosphorylates -H2AX. Molecular and Cellular Biology. 2010; 30:1368-1381.

93. Légaré S, Cavallone L, Mamo A, Chabot C, Sirois I, Magliocco A, Klimowicz A, Tonin PN, Buchanan M, Keilty D, et al. The Estrogen Receptor Cofactor SPEN Functions as a Tumor Suppressor and Candidate Biomarker of Drug Responsiveness in Hormone-Dependent Breast Cancers. Cancer research. 2015; 75:4351-4363.

94. Wang D, Zhang P, Gao K, Tang Y, Jin X, Zhang Y, Yi Q, Wang C, Yu L. PLK1 and $\beta$-TrCP-dependent ubiquitination and degradation of Rap1GAP controls cell proliferation. PloS one. 2014; 9:e110296.

95. Sasi W, Sharma AK, Mokbel K. The role of suppressors of cytokine signalling in human neoplasms. Molecular biology international. 2014; 2014:1-24.

96. Egle A, Harris AW, Bouillet P, Cory S. Bim is a suppressor of Myc-induced mouse B cell leukemia. Proceedings of the National Academy of Sciences of the United States of America. 2004; 101:6164-6169.

97. Aqeilan RI, Donati V, Palamarchuk A, Trapasso F, Kaou M, Pekarsky Y, Sudol M, Croce CM. WW domain-containing proteins, WWOX and YAP, compete for interaction with ErbB-4 and modulate its transcriptional function. Cancer research. 2005; 65:6764-6772.

98. Aqeilan RI, Palamarchuk A, Weigel RJ, Herrero JJ, Pekarsky Y, Croce CM. Physical and functional interactions between the Wwox tumor suppressor protein and the AP-2gamma transcription factor. Cancer research. 2004; 64:8256-8261.

99. Gaudio E, Palamarchuk A, Palumbo T, Trapasso F, Pekarsky Y, Croce CM, Aqeilan RI. Physical association with WWOX suppresses c-Jun transcriptional activity. Cancer research. 2006; 66:11585-11589.

100. Levine AJ, Puzio-Kuter AM. The control of the metabolic switch in cancers by oncogenes and tumor suppressor genes. Science (New York, N.Y.). 2010; 330:1340-1344.

101. Hu C-J, Wang L-Y, Chodosh LA, Keith B, Simon MC. Differential roles of hypoxia-inducible factor 1alpha (HIF-1alpha) and HIF-2alpha in hypoxic gene regulation. Molecular and cellular biology. 2003; 23:9361-9374.

102. Marín-Hernández A, Gallardo-Pérez JC, Ralph SJ, Rodríguez-Enríquez S, Moreno-Sánchez R. HIF-1alpha modulates energy metabolism in cancer cells by inducing over-expression of specific glycolytic isoforms. Mini reviews in medicinal chemistry. 2009; 9:1084-1101.
103. Abu-Remaileh M, Aqeilan RI. Tumor suppressor WWOX regulates glucose metabolism via HIF $1 \alpha$ modulation. Cell death and differentiation. 2014; 21:1805-1814.

104. Moretti M, Bennett J, Tornatore L, Thotakura AK, Franzoso G. Cancer: NF- $\kappa \mathrm{B}$ regulates energy metabolism. The international journal of biochemistry \& cell biology. 2012; 44:2238-2243.

105. Kowaltowski AJ, de Souza-Pinto NC, Castilho RF, Vercesi AE. Mitochondria and reactive oxygen species. Free radical biology \& medicine. 2009; 47:333-343.

106. Comhair SAA, Erzurum SC. The regulation and role of extracellular glutathione peroxidase. Antioxidants \& redox signaling. 2005; 7:72-79.

107. Townsend DM, Tew KD. The role of glutathione-Stransferase in anti-cancer drug resistance. Oncogene. 2003; 22:7369-7375.

108. Benedettini E, Sholl LM, Peyton M, Reilly J, Ware C, Davis L, Vena N, Bailey D, Yeap BY, Fiorentino M, Ligon AH, Pan B-S, Richon V, et al. Met activation in non-small cell lung cancer is associated with de novo resistance to EGFR inhibitors and the development of brain metastasis. The American journal of pathology. 2010; 177:415-423.

109. Pietras K, Rubin K, Sjöblom T, Buchdunger E, Sjöquist M, Heldin C-H, Ostman A. Inhibition of PDGF receptor signaling in tumor stroma enhances antitumor effect of chemotherapy. Cancer research. 2002; 62:5476-5484.

110. Miyake H, Nelson C, Rennie PS, Gleave ME. Acquisition of chemoresistant phenotype by overexpression of the antiapoptotic gene testosterone-repressed prostate message- 2 in prostate cancer xenograft models. Cancer research. 2000; 60:2547-2554.

111. Zellweger T, Kiyama S, Chi K, Miyake H, Adomat H, Skov K, Gleave ME. Overexpression of the cytoprotective protein clusterin decreases radiosensitivity in the human LNCaP prostate tumour model. BJU international. 2003; 92:463-469.

112. Aslanian AM, Fletcher BS, Kilberg MS. Asparagine synthetase expression alone is sufficient to induce 1-asparaginase resistance in MOLT-4 human leukaemia cells. The Biochemical journal. 2001; 357:321-328.

113. Akiyama T, Dass CR, Choong PFM. Bim-targeted cancer therapy: a link between drug action and underlying molecular changes. Molecular cancer therapeutics. 2009; 8:3173-3180.

114. Liu Ax, Cerniglia GJ, Bernhard EJ, Prendergast GC. RhoB is required to mediate apoptosis in neoplastically transformed cells after DNA damage. Proceedings of the National Academy of Sciences of the United States of America. 2001; 98:6192-6197.

115. Bredel M, Scholtens DM, Yadav AK, Alvarez AA, Renfrow JJ, Chandler JP, Yu ILY, Carro MS, Dai F, Tagge MJ, Ferarese R, Bredel C, Phillips HS., et al. NFKBIA deletion in glioblastomas. The New England journal of medicine. $2011 ; 364: 627-637$. 
116. Jin Y, Penning TM. Aldo-keto reductases and bioactivation/ detoxication. Annual review of pharmacology and toxicology. 2007; 47:263-292.

117. Kim J-S, Chang JW, Park JK, Hwang S-G. Increased aldehyde reductase expression mediates acquired radioresistance of laryngeal cancer cells via modulating p53. Cancer biology \& therapy. 2012; 13:638-646.

118. L'Espérance S, Popa I, Bachvarova M, Plante M, Patten N, Wu L, Têtu B, Bachvarov D. Gene expression profiling of paired ovarian tumors obtained prior to and following adjuvant chemotherapy: molecular signatures of chemoresistant tumors. International journal of oncology. 2006; 29:5-24.

119. Ali A, Creevey L, Hao Y, McCartan D, O'Gaora P, Hill A, Young L, McIlroy M. Prosaposin activates the androgen receptor and potentiates resistance to endocrine treatment in breast cancer. Breast cancer research: BCR. 2015; 17:123.

120. Canals A, Ribó M, Benito A, Bosch M, Mombelli E, Vilanova M. Production of engineered human pancreatic ribonucleases, solving expression and purification problems, and enhancing thermostability. Protein expression and purification. 1999; 17:169-181.

121. Ribó M, Benito A., Canals A., Nogués M V., Cuchillo CM, Vilanova M. Purification of engineered human pancreatic ribonuclease. Methods in Enzymology. 2001; 341:221-234.

122. Pace CN, Vajdos F, Fee L, Grimsley G, Gray T. How to measure and predict the molar absorption coefficient of a protein. Protein science: a publication of the Protein Society. 1995; 4:2411-2423.

123. Liscovitch M, Ravid D. A case study in misidentification of cancer cell lines: MCF-7/AdrR cells (re-designated NCI/ ADR-RES) are derived from OVCAR-8 human ovarian carcinoma cells. Cancer Letters. 2007; 245:350-352.

124. Ritchie ME, Silver J, Oshlack A, Holmes M, Diyagama D, Holloway A, Smyth GK. A comparison of background correction methods for two-colour microarrays. Bioinformatics (Oxford, England). 2007; 23:2700-2707.

125. Cleveland W, Devlin S. Locally Weighted Regression: An Approach to Regression Analysis by Local Fitting. Journal of the American Statistical Association. 1988; 83:596-610.

126. Bolstad BM, Irizarry RA, Astrand M, Speed TP. A comparison of normalization methods for high density oligonucleotide array data based on variance and bias. Bioinformatics (Oxford, England). 2003; 19:185-193.

127. Breitling R, Armengaud P, Amtmann A, Herzyk P. Rank products: a simple, yet powerful, new method to detect differentially regulated genes in replicated microarray experiments. FEBS letters. 2004; 573:83-92.

128. Edgar R, Domrachev M, Lash AE. Gene Expression Omnibus: NCBI gene expression and hybridization array data repository. Nucleic acids research. 2002; 30:207-210.

129. Pfaffl MW, Pfaffl MW. A new mathematical model for relative quantification in real-time RT-PCR. Nucleic acids research. 2001; 29:e45. 